\title{
COMPARISON BETWEEN NEUROPSYCHOLOGICAL EVALUATION INSTRUMENTS FOR SEVERE DEMENTIA
}

\author{
José Roberto Wajman, Paulo Henrique F. Bertolucci
}

\begin{abstract}
Objective: To study the correlation between two tools for cognitive evaluation, Mini-Mental State Examination-severe (MMSE-s) and Severe Impairment Battery (SIB), and the Bristol Daily Activities Functional Scale. Method: 50 patients from the Behavioral Neurology Section - EPM-UNIFESP - were evaluated. Mean age was $76.8 \pm 7.9$ (range 57 to 95); $32 \%$ were males; mean education was $5.0 \pm 2.3$ years (range 4 to 15); mean disease duration was $3.9 \pm 1.5$ years (range 2 to 10). Results: Preliminary results in a small sample drawn from the study group do indicate a difference between the three cognitive scales. SIB and MMSE-s had a better correlation with functional score than MMSE, and MMSE-s had a correlation slightly better than SIB. Conclusion: These data indicate that it is possible to follow dementia patients up to severe stage as long as adequate instruments are used, and that there may be differences between scales with regard to sensitivity.
\end{abstract}

KEY WORDS: cognitive tests, daily activities functional scale, dementia.

\section{Comparação de instrumentos de avaliação neuropsicológica para a demência grave}

RESUMO - Objetivo: Avaliar a correlação entre dois instrumentos de avaliação cognitiva, o Mini-Exame do Estado Mental-grave (MEEM-g) e a Bateria para Comprometimento Grave (SIB), e compara-los com a Escala Funcional de Atividades Diárias Bristol. Método: Foram avaliados 50 pacientes provenientes do Setor de Neurologia do Comportamento - UNIFESP-EPM - com idade entre 57 e 95 anos (média 76,84 anos, desviopadrão 7,94 anos e mediana 77,00 anos); 16 (32,0\%) eram do sexo masculino; tempo de escolaridade era 4 a 15 anos (média 5,08 2,31 anos e mediana 4,00 anos). Resultados: Foi possível observar aspectos de sensibilidade entre o MEEM tradicional e os outros dois instrumentos de avaliação para fases avançadas. Conclusão: É possível seguir acompanhando o paciente demenciado, mesmo em fases avançadas da doença, em relação às avaliações cognitiva e funcional.

PALAVRAS-CHAVE: testes cognitivos, escala funcional de atividades diárias, demência.

For a long time Alzheimer disease (AD) was considered a rare disorder and four or five decades ago classical papers on this disease failed to mention details of its clinical picture ${ }^{1}$. According to MedLine only 42 papers with $A D$ as a key word were published in 1975 (compared with 1285 in the first 6 months of 2005).

$A D$ is the most common dementing disorder in the elderly population. Typically this disorder has a insidious onset, with progressive decline of memory, followed by other cognitive areas, such as executive function, language, and praxis ${ }^{2}$. It is estimated that in the United States only more than four million elderly have dementia at a severe stage and another one and half million dementia at mild or moderate stage. It is expected that the population with demen- tia in that country will rise to nine million by $2030^{3}$. Investigations in São Paulo state hinterland showed the same trend ${ }^{4}$, with an estimated 750 thousands to one million Brazilians with dementia. The realization of the huge dimension of AD has brought a lot of interest in treating and following these patients as they progress to more advanced disease stages. Many scales have been developed for the evaluation of pre-clinical, mild and moderate stages ${ }^{5}$, but the same is not true for the evaluation of patients in more severe stage, for whom relatively few investigations have been undertaken ${ }^{6}$.

The evaluation of cognitive abilities in these patients would fill several clinical and research needs, like the identification of less affected cognitive areas, which could in turn be used by health professionals

Hospital São Paulo, Setor de Neurologia do Comportamento - Disciplina de Neurologia - Escola Paulista de Medicina - UNIFESP São Paulo SP, Brasil.

Received 27 January 2006, received in final form 15 May 2006. Accepted 9 June 2006.

Dr. José Roberto Wajman - Disciplina de Neurologia / Escola Paulista de Medicina / UNIFESP - Rua Botucatu 740 - 04023-900 São Paulo SP - Brasil. E-mail: betowajman@usa.com 
as starting point for the development of compensatory strategies; in the setting of normative data for this population, useful not only in the follow up of this group, but also in evaluating the effect of treatment; in the investigation of the correlation between post mortem neurochemical and neuropathological changes and cognition.

The development and application of standardized and validated neuropsychological scales has had a significative impact in improving diagnostic precision and in the characterization of the cognitive decline associated with $A D^{7}$, but, with disease progression, the use of most scales for neuropsychological evaluation is hampered by the floor effect, with performance near null. Patients are considered as "non testable" when their neuropsychological performance is much under the lower limit, indicating that there is a severe cognitive decline, but, even at a very advanced stage, there might be cognitive areas that are spared. There is ample justification for the statement that little is known about more cognitively and functionally affected patients, in large part due to the low sensitivity for this group of most of the scales in common use.

Cognitive tests for patients in a more severe stage were developed, like the Test for Severe Impairment $(\mathrm{TSI})^{8}$, the Modified Ordinal Scales of Psychological Development ${ }^{9}$ (MOSPD) the Severe Cognitive Impairment Profile $(\mathrm{SCIP})^{10}$. Many of these scales took into consideration the language difficulties of these patients, but for their administering special training and specific material are needed. In the average, their administration takes 40 minutes. These points suggest the ideal scale should as much as possible: 1 ) characterize patients cognitive deterioration level and disease progression; 2) sensitive and easily applicable to the Brazilian population; 3) brief, but evaluating as extensively as possible the cognitive functions; 4) not needing extensive training and a large load of technical resources; 5 ) be useful in longitudinal follow up of pharmacological and non pharmacological treatment.

To this end severe impairment battery (SIB) and mini-mental state-examination-severe (MMSEs) were developed for the evaluation of patients with severe cognitive impairment non testable by the usual cognitive scales ${ }^{11}$. By their very characteristics they might disclose differences among severe stage patients that are not identified by conventional scales. If this is true, performance in these scales would correlate more closely with functional status than conventional scales. This investigation was undertaken to compare the performance in the MMSEs and SIB and the performance in the Bristol Daily Activities Functional Scale; stratification of CDR 2 and 3 patients by SIB and MMSEs score; to compare the stratification by these two scales and by MMSE; correlation between SIB and MMSEs and age, education, and disease duration.

\section{METHOD}

Fifty patients with probable AD (DSM-IV) in moderate to severe stages (CDR 2 and 3) and a MMSE score of 15 or less were included. All patients were recruited from outpatient clinic (Behavioral Neurology Section - Federal University of São Paulo - São Paulo - Brazil) and had an unpaid reliable informant. A written explanation of the research design was read by the responsible for the patient and additional explanations were given when necessary, after which an informed consent was signed. All proceedings were approved by the Institutional Review Board.

To be included patients had to have at least some degree of verbal ability and sighting and hearing enough to be evaluated. Neurological or psychiatric conditions that could impact on cognition were exclusion criteria.

Evaluation was done in a single individual session with mean duration of one and half hour. While SIB and MMSEs were applied to the patient the informant filled the Bristol scale. In half of the patients the order of application was SIB and MMSEs and the reverse for the other half.

Scales - Bristol Daily Activities Functional Scale ${ }^{12}$ is composed by 20 questions to assess daily activities in a scale ranging from 0 to 4 , with a maximum score of 60 . Since incapacity is scored, the higher the score the more the functional incapacity. The informant completed the scale, and any doubts were discussed with the investigator.

The Mini-mental State Examination - severe is based on the original MMSE but includes questions related to autobiographical knowledge, orientation, simpler comands, constructional praxis, phonological loop, semantic verbal fluency, and memory. The score ranges from 0 to 30 and, like the original MMSE, is a pencil and paper test which, takes a mean of 5 minutes to be completed.

The Severe Impairment Battery has 9 sub-items, evaluating social interaction, orientation, visual spatial ability, constructional praxis, language, attention, memory, orientation to own name, and praxis. Cues and repetition of commands are permitted and the score ranges from 0 to 100 (higher scores meaning better performance), there is need of a kit of objects and mean time for the test completion is 25 minutes.

For the translation of SIB and MMSEs the following method was adopted: 1) translation by a professional familiar with the scales; 2 ) translation review by bilingual people with experience in psychogeriatrics; 3) revision by a group representative of the population in which the scales are used; 4) independent back translation; 5) evaluation of the back translation by bilinguals with attention to significant differences in comparison with the original and review of syntaxes and semantic aspects. 
In a preliminary step all variables went through a descriptive analysis. For quantitative variables minimum and maximum scores were observed and medians, means, and square deviation were calculated. For qualitative analysis absolute and relative frequencies were calculated.

Non parametric Mann-Whitney test was used for the comparison between groups, since normal distribution was rejected. For the correlation of variables Spearman coefficient was used. Significance level was set at $5 \%$.

\section{RESULTS}

Fifty patients with age ranging from 57 and 95 years (mean 76,84 $\pm 7,94$; median 77,00). Sixteen $(32,0 \%)$ patients were male. Disease duration ranged from 2 to 10 years (mean 3,98 $\pm 1,53$; median 4,00) and education ranged from 4 to 15 years (mean $5,08 \pm 2,31$; median 4,00). Results are shown on Table 1.

As shown in Table 2, there was a significant positive correlation between age and MMSE and SIB scores. There was a significant negative correlation between disease duration and MMSE and SIB scores and a positive correlation between disease duration and Bristol scale. There was no correlation between education or disease duration and these scores.

In Table 3 the values of correlation among the scales are shown. There is a significant positive correlation between MMSE and MMSEs and SIB and between MMSEs and SIB. There is a significant negative correlation between MMSE and Bristol scale. There is a low but significant correlation between MMSEs and Bristol and no correlation was found between SIB and Bristol scale.

As shown in Table 4, and as expected, there is a significant correlation between disease duration and CDR, and between CDR and MMSE, MMSEs and SIB score. On the other hand, no correlation was found between CDR and age or education. Finally, as shown in the dispersion graphic (Figure), there was a positive and significant correlation between both scales, MMSE and MMSEs.

\section{DISCUSSION}

As results have shown, both scales, MMSEs and SIB, are more sensitive for the evaluation of severe stage dementia patients than conventional screening scales like MMSE. With regard to MMSEs, Harrel and cols ${ }^{11}$ have shown that it is comparable or even superior to that of MMSE in this group of patients. In a preliminary report Engelhardt and cols $^{13}$, suggested that MMSEs may give a better picture of patients with very low traditional MMSE scores.

There was no correlation between both scales and education ${ }^{14,15}$. There is a large amount of research on the correlation between education and cognitive per-

Table 1. Means, standard deviation (SD), median and range of scores in the 50 patients.

\begin{tabular}{lccccc}
\hline Scale & Mean & SD & Median & Lower & Higher \\
\hline Mini-mental State Examination & 9.48 & 2.96 & 10.00 & 3.00 & 14.00 \\
Mini-mental State Examination-severe & 23.66 & 4.01 & 25.00 & 15.00 & 29.00 \\
Severe Impairment Battery & 80.74 & 9.92 & 84.00 & 62.00 & 96.00 \\
Bristol & 28.64 & 7.91 & 28.00 & 11.00 & 46.00 \\
\hline
\end{tabular}

Table 2. Spearman correlation coefficient, $p$ value, age, disease duration, and education in the 50 patients.

\begin{tabular}{lccccc}
\hline \multirow{2}{*}{ Variable } & & \multicolumn{4}{c}{ Scales } \\
\cline { 3 - 6 } Age & & MMSE & MMSEs & SIB & Bristol \\
\cline { 3 - 6 } & $\mathrm{r}$ & 0.460 & 0.208 & 0.358 & 0.081 \\
Education & $\mathrm{p}$ & 0.001 & 0.147 & 0.011 & 0.578 \\
& $\mathrm{p}$ & -0.227 & -0.124 & -0.078 & 0.243 \\
Disease & $\mathrm{r}$ & -0.113 & 0.390 & 0.588 & 0.089 \\
Duration & $\mathrm{p}$ & 0.006 & -0.117 & -0.478 & 0.497 \\
\hline
\end{tabular}

$r$, Spearman correlation; $p$, significance level $5 \%$.
Table 3. Spearman correlation and $p$ value between the scales in the 50 patients.

\begin{tabular}{lcccc}
\hline \multirow{2}{*}{ Scale } & \multicolumn{3}{c}{ Scales } \\
\cline { 3 - 5 } MMSE & $\mathrm{r}$ & 0.692 & 0.675 & -0.445 \\
& $\mathrm{p}$ & $<0.001$ & $<0.001$ & 0.001 \\
MMSEs & $\mathrm{r}$ & - & 0.638 & -0.289 \\
& $\mathrm{p}$ & & $<0,001$ & 0,042 \\
SIB & $\mathrm{r}$ & & - & -0.270 \\
& $\mathrm{p}$ & & & 0.058 \\
\hline
\end{tabular}

$r$, Spearman correlation; $p$, significance level $5 \%$. 
Table 4. Values of means, square deviation, median with relation to age, disease duration, education and scales scores according to $C D R$.

\begin{tabular}{lcccccccc}
\hline Variable & CDR & $\mathrm{N}$ & Mean & SD & Median & Lower & Higher & $\mathrm{p}^{*}$ \\
\hline Age & 2 & 32 & 78.16 & 8.76 & 78.50 & 57.00 & 95.00 & 0.052 \\
& 3 & 18 & 74.50 & 5.73 & 74.00 & 62.00 & 84.00 & \\
Education & 2 & 32 & 4.84 & 2.53 & 4.00 & 4,00 & 15.00 & 0.057 \\
& 3 & 18 & 5.50 & 1.86 & 4.00 & 4.00 & 8.00 & \\
Disease & 2 & 32 & 3.66 & 1.29 & 3.00 & 2.00 & 8.00 & 0.038 \\
duration & 3 & 18 & 4.56 & 1.79 & 4.50 & 2.00 & 10.00 & \\
MMSE & 2 & 32 & 11.25 & 1.72 & 12.00 & 8.00 & 14.00 & $<0.001$ \\
& 3 & 18 & 6.33 & 1.88 & 7.00 & 3.00 & 9.00 & \\
MMSEs & 2 & 32 & 25.97 & 2.67 & 27.00 & 16.00 & 29.00 & $<0.001$ \\
& 3 & 18 & 19,56 & 2,33 & 19,00 & 15,00 & 23,00 & \\
SIB & 2 & 32 & 85.88 & 6.15 & 86.50 & 66.00 & 96.00 & $<0.001$ \\
& 3 & 18 & 71,61 & 8,76 & 68,00 & 62,00 & 89,00 &
\end{tabular}

*Mann-Whitney's significance level.

formance, but our results could have two explanations: the tasks in these two scales are quite simple and there is a clear floor effect in control or less advanced dementia patients; the education bias might disappear at a relatively early stage of dementias.

The findings in our study suggest that MMSEs may be useful in research and clinical practice, for the evaluation of severe dementia patients. There are methodological and practical advantages, like the brief period of time for its application, a mean of $5 \mathrm{~min}$, the need of paper and pencil only, and the simple training that is required by the examiner. Additionally its structure is similar to that of traditional MMSE, which has a widespread popularity among health workers dealing with dementia.

Howard and cols ${ }^{16}$ pointed that cognitive and functional tools could and should be jointly used to improve the clinical impression of the severe dementia patient status in a more natural setting. On this line of reasoning, co-variance analysis showed that, though at a low level, there is a correlation between MMSEs and Bristol scale, and it is possible to conclude that this scale and what patient actually is in "real life".

Ferraro and cols $^{17}$, point to another aspect relevant to this investigation, the need of standardizing the creation and modification of tools for neuropsychological evaluation, with regard to their inner struc-

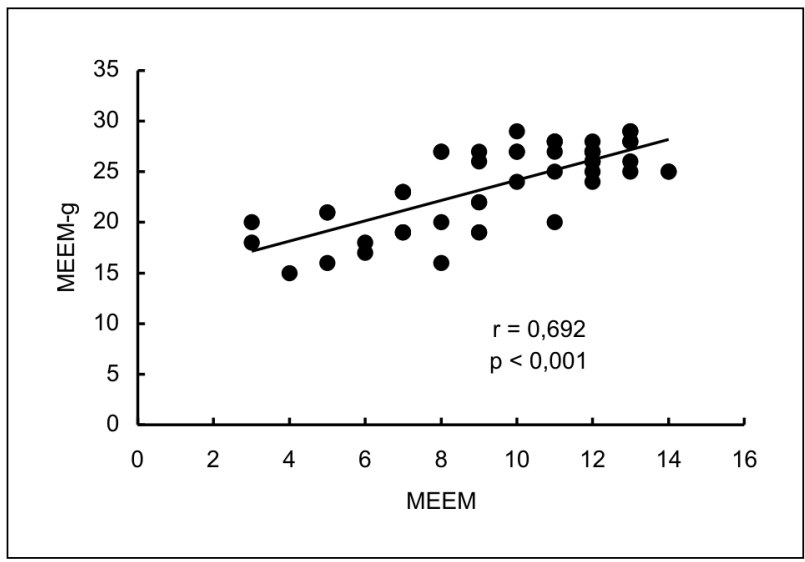

Figure. Graphic correlation between MMSE and MMSEs.

ture and normative data that might de relevant to other cultures. The same is suggested by Bell and cols. ${ }^{18}$, when using cognitive batteries in Canada, and reaching the conclusion that it is necessary to review the characteristics of dementia progression, as a prerequisite to adapt these tools so that they become more precise for more advanced stages.

The results of this investigation are in accordance with those of other centers and meet a need of our country with respect to the evaluation and follow up of severe dementia patients. Considering that survival in dementia patients is increasing and new therapies are being tried, this issue will become increasingly crucial. 


\section{REFERENCES}

1. Walshe F. Diseases of the nervous system. London: Livingstone, 1958.

2. Gauthier S. Clinical diagnosis and management of Alzheimer disease, 2nd Ed. London: Martin Dunitz, 2001.

3. Jonsson B, Jonsson L, Wimo A. Cost of dementia. In May M, Sartorious $\mathrm{N}$ (eds). Dementia: WPA series evidence and experience in psychiatry. London: John Wiley \& Sons, 2000: 335-363.

4. Nitrini R, Carameli P, Herrera Jr E, et al. Incidence of dementia in a community-dwelling Brazilian population. Alz Dis Assoc Disord 2004; 18:241-246.

5. Morris J, Edland S, Clark C, et al. The consortium to establish a registry for Alzheimer's disease (CERAD): Part IV. Neurology 1993;43: 2457-2465.

6. Saxton J, McGonigle-Gibso, K, Swihart A, et al. Assessment of the severely impaired patient: description and validation of a new neuropsychological test battery. Psychological Assessment. J Consult Clin Psychol 1990;2:298-303.

7. Bonds MW, Salmon DP, Butters N. Neuropsychological features of memory disorders in Alzheimer's disease. In Terry RD, Katzmann R, Bick K (eds). Alzheimer`s disease. New York: Raven Press, 1994:41-63.

8. Albert M, Cohen C. The Test for severe impairment: an instrument for the assessment of patients with severe cognitive dysfunction. J Am Ger Soc 1992;40:449-453.

9. Auer SR, Sclan SG, Yaffee RA, et al. The neglected half of Alzheimer disease: cognitive and functional of severe dementia. J Am Ger Society 1994;42:1266-1272.

10. Peavy GM, Salmon DP, Rice VA, et al. Neuropsychological assessment of severely demented elderly: the severe cognitive imparment profile. Arch Neurol 1996;53:367-372.

11. Harrell LE, Marson D, Chatterjee A, et al. The severe Mini-Mental State Examination: a new neuropsychologic instrument for the bedside assessment of severely impaired patients with Alzheimer disease. Alz Dis Assoc Disord 2000;14:168-175.

12. Bucks RS, Ashworth DL, Wilcock GK, et al. Assessment of activities of daily living in dementia: development of the Bristol Activities of Daily Living Scale. Age Ageing 1996:25:113-120.

13. Engelhardt E, Rocha M, Laks J, et al. O Mini-Exame do Estado Mental Grave: resultados preliminares de validação de uma tradução brasileira. Arq Neuropsiquiatr 2003;61(Suppl 2):S41.

14. Brito-Marques PR, Cabral-Filho JE. Influence of age and schooling on the performance in a modified Mini-Mental State Examination version: a study in Brazil Northeast. Arq Neuropsiquiatr 2005;62:206-211.

15. Xu G, Meyer JS, Huang $Y$, et al. Adapting mini-mental state examination for dementia screening among illiterate or minimally educated elderly chinese. Int J Geriatr Psychiatry 2003;13:609-616.

16. Howard RJ, Narvaez JM, Hallam B, et al. Neuropsychological and functional measures of severity in Alzheimer`s disease, frontotemporal dementia, and semantic dementia. Alz Dis Assoc Disord 2004;18:202-207.

17. Ferraro FR, McDonald LR. More culturally sensitive neuropsychological tests (and normative data) needed. Alz Dis Assoc Disord 2005 19:53-54.

18. Behl P, Stefurak TL, Black SE. Progress in clinical neurosciences: cognitive markers of progression in Alzheimer`s disease. Can J Neurol Sci $2005 ; 32: 140-151$ 